\title{
FASE-CPHG study: a panoramic snapshot of difficult-to-treat, severe asthma in French nonacademic hospitals
}

\author{
Laurent Portel ${ }^{1}$, Eric Parrat ${ }^{2}$, Cécilia Nocent-Ejnaini ${ }^{3}$, Gilles Mangiapan ${ }^{4}$, \\ Anne Prud'homme ${ }^{5}$, Jean-Philippe Oster ${ }^{6}$, Corinne Aperre de Vecchi ${ }^{7}$, \\ Cyril Maurer $^{8}$, Chantal Raherison ${ }^{9}$ and Didier Debieuvre (i) ${ }^{10}$
}

\begin{abstract}
Affiliations: ${ }^{1}$ Centre Hospitalier de Libourne, Libourne, France. ${ }^{2}$ Centre Hospitalier de Polynésie Française, Hôpital du Taaone, Papeete, French Polynesia. ${ }^{3}$ Centre Hospitalier de la Côte Basque, Bayonne, France. ${ }^{4}$ Centre Hospitalier Intercommunal de Créteil, Service de Pneumologie, Créteil, France. ${ }^{5}$ Centre Hospitalier Intercommunal de Bigorre, Service de Pneumologie, Tarbes, France. ${ }^{6}$ Centre Hospitalier Louis Pasteur, Service de Pneumologie, Colmar, France. ${ }^{7}$ Centre Hospitalier d'Argenteuil, Argenteuil, France. ${ }^{8}$ Groupe Hospitalier Intercommunal Le Raincy-Montfermeil, Montfermeil, France. ${ }^{9}$ Groupe Hospitalier Sud, Hôpital du Haut-Lévêque, Pessac, France. ${ }^{10}$ Groupe Hospitalier de la Région Mulhouse Sud-Alsace, Hôpital Émile Muller, Service de Pneumologie, Mulhouse, France.
\end{abstract}

Correspondence: Laurent Portel, Centre Hospitalier de Libourne, BP 199, 33505 Libourne, France. E-mail: laurent.porteldach-libourne.fr

\section{ABSTRACT}

Background: Real-world data describing management of patients with severe asthma are limited. To address this issue, we conducted FASE-CPHG (France Asthme Sevère - Collège des Pneumologues des Hôpitaux Généraux), a descriptive, multicentric, and observational cross-sectional study.

Methods: French pulmonologists from nonacademic hospitals completed questionnaires on patient characteristics and ongoing asthma treatment for severe asthmatic patients observed during the inclusion period. In addition, we collected data from patients via self-assessment questionnaires.

Findings: 104 physicians recruited 1502 patients within 1 year. The mean age of the 1465 patients analysed was $54.4 \pm 16.1$ years. Severe asthmatic patients were more frequently female $(63 \%)$, with a history of atopy (65\%). Most patients remained poorly controlled or uncontrolled, with an important difference between physicians' opinion and the Global Initiative for Asthma criteria (63\% versus 96\%). The most common comorbidities included ear, nose and throat diseases (59\% of cases); anxiety (40\%); and gastro-oesophageal reflux disease (39\%). Allergic sensitisation tests and/or blood eosinophil count evaluation, and spirometry were performed in $92 \%$ and $98 \%$ of patients, respectively. The mean eosinophil count and total serum $\operatorname{IgE}$ were 437 cells $\cdot \mathrm{mm}^{-3}$ and $546 \mathrm{UI} \cdot \mathrm{L}^{-1}$, respectively. In addition to high doses of inhaled corticosteroids plus long-acting $\beta_{2}$-agonists, patients were receiving leukotriene receptor antagonists (52\%), anticholinergic drugs (34\%), anti IgE (27\%) and oral corticosteroids (17\%); 65\% adhered to their treatment.

Interpretation: This study provides insight into the characteristics and management of severe asthma in France and may help improve knowledge on this pathology, which represents a high burden to healthcare.

@ERSpublications

This is a large study of severe asthma, with $>1500$ patients included, that gives new insights into epidemiological data, patients' characteristics and disease management http://bit.ly/2K9NqMT

Cite this article as: Portel L, Parrat E, Nocent-Ejnaini C, et al. FASE-CPHG study: a panoramic snapshot of difficult-to-treat, severe asthma in French nonacademic hospitals. ERJ Open Res 2019; 5: 00069-2019 [https://doi.org/10.1183/23120541.00069-2019].

This article has supplementary material available from openres.ersjournals.com

Received: 13 March 2019 | Accepted after revision: 30 July 2019

Copyright $\odot$ ERS 2019. This article is open access and distributed under the terms of the Creative Commons Attribution Non-Commercial Licence 4.0. 


\section{Introduction}

Asthma is an inflammatory chronic airway disease characterised by dyspnoea, wheeze, cough and chest tightness. It is a frequent disease that affects $>300$ million people worldwide [1] and $\sim 5-10 \%$ of the general population in France, according to Santé Publique France, the French national public health agency. However, epidemiological data regarding severe asthma in real life are scarce. Estimations vary from $5-10 \%$ [2] to $>10 \%$ [3]. Recently, the asthmaPOP survey estimated prevalence of severe asthma in France to be $3.8 \%[4]$.

The European Respiratory Society, the American Thoracic Society and local French guidelines have defined asthma as severe when it requires treatment with high dose of inhaled corticosteroids (ICS) plus long-acting $\beta_{2}$-agonists (LABAs) together with an add-on treatment to prevent it from becoming "uncontrolled" or when it remains uncontrolled despite this therapy $[5,6]$.

Severe asthma cases represent the majority of health costs for asthma, which are mainly due to indirect costs (absenteeism, lack of productivity) rather than medical costs, like medication, even if new treatments are relatively expensive. The costs drastically increase as disease control decreases, with the cost being five times higher for uncontrolled asthma [7].

Furthermore, severe asthma has been identified as a heterogeneous disease with various clinical phenotypes of differing severity, which develop through distinct mechanisms $[8,9]$. The identification and characterisation of asthma subtypes have already led to the development of new therapies, including monoclonal antibodies directed against immunoglobulin (Ig)E (omalizumab) [6] or against interleukin (IL)-5 (mepolizumab, reslizumab, benralizumab) [10, 11], and will be valuable for developing new drugs and defining better asthma management.

To date, severe asthma remains poorly understood, and the impact of recent therapeutic advances on the management of this disease has been insufficiently studied. The aim of our study was to describe the clinical characteristics of adults with severe asthma and their management in French nonacademic hospitals.

\section{Research in context}

Evidence before this study

Data on severe asthma in real life are scarce.

\section{Added value of this study}

Our study was based on $>1500$ patients with severe asthma. We report updated data on epidemiology and biology and major information on disease control and treatment adherence, which are key for appropriate management of asthma. Moreover, no previous studies have included such a large sample of adult patients with severe asthma. Thus, we believe our study provides a great contribution to the existing literature.

\section{Implications of all the available evidence}

This article will be of interest because our results can assist clinicians in patient characterisation and improve their daily practice. Moreover, in this era of new treatments based on biological findings, our data will be of great interest for ongoing research in the industry.

\section{Methods}

Study population

The Collège des Pneumologues des Hôpitaux Généraux (CPHG) is a collaborative group of pulmonologists working in nonacademic hospitals. This structure has long been invested in clinical research, especially focusing on lung cancer, and has conducted two large epidemiological studies, KBP 2000 and KBP 2010, including $>12000$ patients [12, 13].

We initiated FASE-CPHG (France Asthme Sevère - Collège des Pneumologues des Hôpitaux Généraux) in 2016 as a descriptive, multicentric and observational cross-sectional study conducted in general hospitals in France. The study was approved by the local ethics committee (Comité Consultatif sur le Traitement de l'Information en matière de Recherche dans le domaine de la Santé) and was conducted according to the French law and guidelines on epidemiological and descriptive studies.

Pulmonologists from an extensive list of practitioners were contacted to confirm their willingness to participate in the FASE-CPHG observational study. During the inclusion period, between May 2016 and July 2017, selected pulmonologists were asked to recruit all patients who met the eligibility criteria to ensure exhaustivity. For the same reason, patients who refused to participate in the study were logged in a noninclusion register. 
Patients fulfilling all following criteria were included in the study: age $>18$ years and severe asthma diagnosis according to the physician and based on the Global Initiative for Asthma (GINA) [14]. The physician informed all subjects about the study during a regular visit and patients were encouraged to participate. Oral consent was obtained from all patients before entering this non-interventional study. Patients diagnosed with solid cancer or malignant haemopathy, as well as those who refused to participate in the study, were excluded.

\section{Patient data collection}

During a regular patient visit, physicians completed a secure electronic case report form (eCRF) on patients' characteristics (sociodemographic data, potential asthma triggers, medical history, comorbidities, clinical parameters) and ongoing asthma treatment for all patients seen during the study period.

In addition, patients were required to fill in a paper self-assessment questionnaire comprising items on asthma control (Asthma Control Test $(\mathrm{ACT})$ ), anxiety and depression (Hospital Anxiety and Depression Scale (HADS)) and medication adherence (four-item Morisky Medication Adherence Assessment Scale (MMAS-4)).

\section{Data management}

Data were entered into databases managed by Kappa Santé (Paris, France). Duplicates were identified using indirectly nominative data (initial age and sex) and reviewed by the participating pulmonologists. In addition to the online control present on the eCRF, a scientific committee reviewed data before database freeze for other errors, omissions or inconsistencies.

Patients enrolled by participating physicians with no completed CRFs were removed from the analysis.

\section{Statistical analyses}

All statistical analyses were performed using SAS (version 9.4; SAS Institute, Cary, NC, USA). p-values $<0.05$ were regarded as statistically significant.

Qualitative variables are presented as raw values and frequencies, and the numbers of missing data are specified. Quantitative data are expressed as numbers of analysed values or mean \pm SD.

According to the GINA criteria, severe asthma is defined as asthma that requires step 4 or 5 treatment to prevent it from becoming "uncontrolled" or asthma that remains "uncontrolled" despite this treatment [14]. Uncontrolled patients administered with step 3 treatment were also considered as severe asthmatics, as the adjustment strategy in cases of uncontrolled asthma for 3 months would be to step-up treatment to step 4. After validation by the physicians, patients treated only with short-acting $\beta_{2}$-agonists (SABA) were excluded from analyses, as they were considered to be nonsevere asthma patients according to the GINA criteria.

Asthma control was evaluated using the ACT, a five-item questionnaire on activity limitation, shortness of breath, night symptoms, use of rescue medication and self-perception of asthma control. Each parameter was scored from 1 (poorly controlled) to 5 (well controlled). The HADS was used to evaluate anxiety and depression symptoms in patients. This scale contains 14 items divided in two subscales: one for anxiety (HADS-A) and one for depression (HADS-D). A score $\geqslant 11$ on either scale indicates a definitive case, whereas scores $<7$ generally indicate an absence of the issue. The MMAS-4 questionnaire was used to assess medication adherence [15-17].

\section{Role of the funding source}

The funding bodies had no role in the conception of this manuscript, and they did not participate in any way in the design of the study, analysis of results, writing or revision of the manuscript.

The corresponding author confirms that he had full access to all the data in the study and had final responsibility for the decision to submit for publication.

\section{Results}

Participation of pulmonologists and patient recruitment

Patients were enrolled between May 2016 and July 2017. Out of the 1502 patients initially recruited by 104 physicians, 1465 completed the questionnaires and had available data, and were therefore eligible for analysis (figure 1). In the entire study population, questionnaires were missing from 98 patients.

\section{Confirmation of severe asthma}

Among the 1465 patients analysed, 95\% were confirmed as severe asthmatic patients according to the GINA classification. For 78 patients, severe asthma was not confirmed, mainly due to the very short 


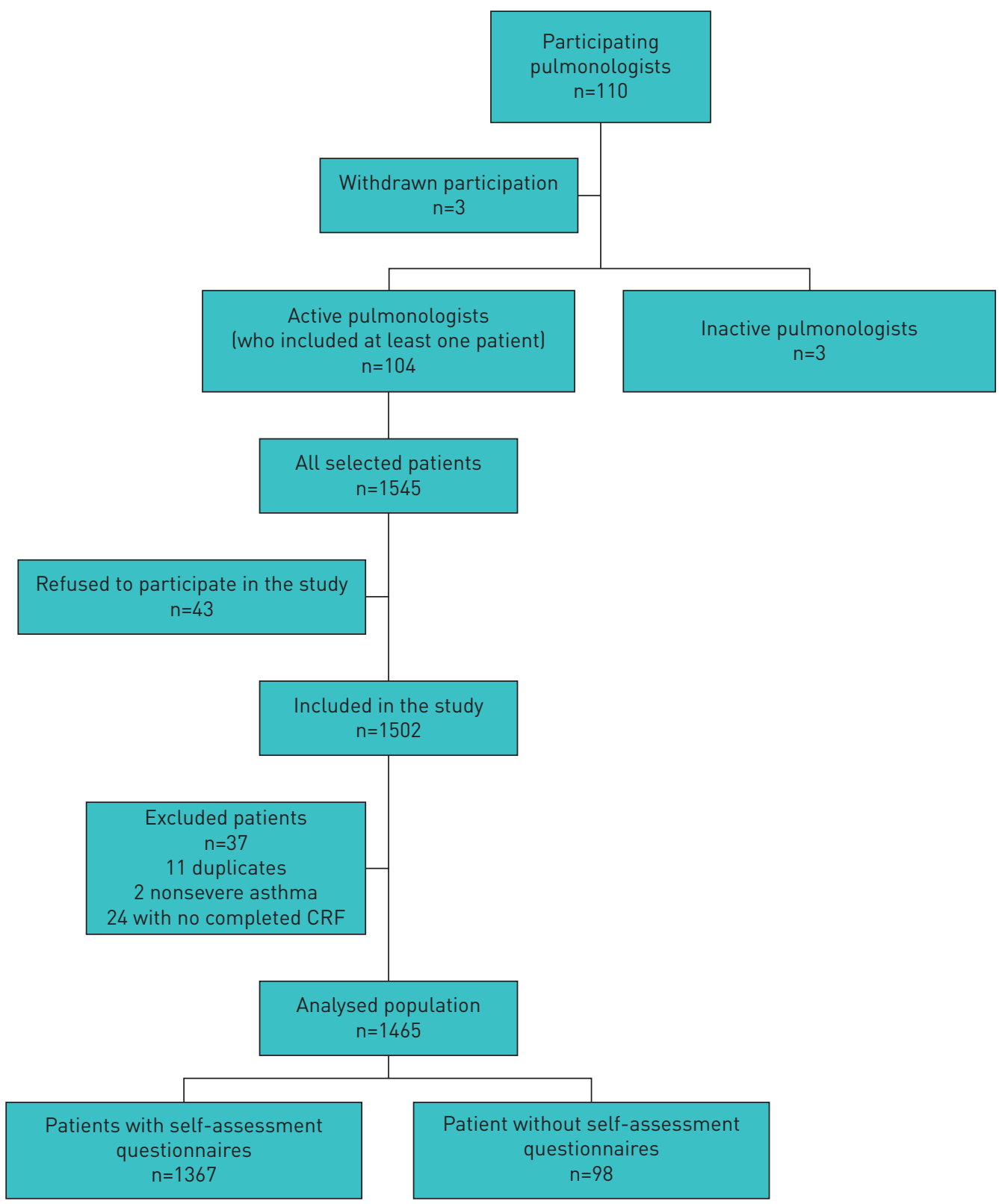

FIGURE 1 Study flow chart: pulmonologist participation and patient recruitment. CRF: case report form.

follow-up ( $<6$ months) by the pulmonologist (in $94 \%$ of cases; table 1 ). Since results from the confirmed severe asthma population according to the GINA were coherent with those of the entire study population, the following analysis was performed on the 1465 patients.

\section{Patient characteristics}

Characteristics of patients are shown in table 2. Most of the patients were female (63\%), with an overall mean age of 54.4 years. The mean body mass index was $27.6 \mathrm{~kg} \cdot \mathrm{m}^{-2} .32 \%$ of the population were overweight and $30 \%$ were obese. Most patients were nonsmokers (60\%). Active smokers represented $12 \%$ of patients, smoking an average of 18 packs per year, among smokers and ex-smokers. There was a high incidence of atopy history, with personal atopy observed in $65 \%$ of patients. Regarding environmental exposures, $42 \%$ of the population was exposed to domestic animals, and approximately half of the patients (48\%) lived in an urban environment.

\section{Asthma control}

A significant difference in asthma control was observed between asthma assessment according to pulmonologists' judgment and to the GINA criteria ( $\mathrm{p}<0.0001$; table 3$)$. Physicians considered that asthma 


\begin{tabular}{|c|c|c|c|c|}
\hline & Confirmed severe asthma & Not confirmed severe asthma & Missing data & Total \\
\hline Subjects & 1377 & 78 & 10 & 1465 \\
\hline \multicolumn{5}{|l|}{ GINA step } \\
\hline Step 1 & 0 & $1(1)$ & & $1(0)$ \\
\hline Step 2 & 0 & 0 & & 0 \\
\hline Step 3 & $24(2)$ & $8(10)$ & & $32(2)$ \\
\hline Step 4 & $565(41)$ & $41(53)$ & & $606(41)$ \\
\hline Step 5 & 788 (57) & $28(36)$ & & $816(56)$ \\
\hline Unknown & & & 10 & $10(1)$ \\
\hline $\begin{array}{l}\text { Patient follow-up } \\
<6 \text { months }\end{array}$ & 0 & $73(94)$ & & $73(5)$ \\
\hline
\end{tabular}

was well controlled in $37.4 \%$ of patients, while this number was only $4 \%$ according to the GINA criteria. A 96.7\% association was found between asthma control according to the physician and that according to the GINA criteria regarding uncontrolled patients. A significant association was found between well-controlled asthma and high adherence level $(\mathrm{p}<0.0001$; supplementary table S1)

\section{Asthma history and clinical presentation}

The mean age at diagnosis was 26.9 years. Asthma occurred before the age of 12 years in $34 \%$ of patients, while in $37 \%$, asthma onset was between 13 and 39 years of age. Approximately half of the patients (52\%) had a history of acute severe asthma. Several patients (65\%) had experienced frequent exacerbations in the previous year, with an average number of 2.5 severe exacerbations per patient per year. Exacerbations led to an average number of 35.3 sick days over the previous year (table 4 ).

The most frequent asthma-related conditions were ear, nose and throat (ENT) diseases (identified in $58.9 \%$ of the patients), atopic dermatitis (15.4\%) and drug allergy (14.1\%). Chronic rhinitis was the most common ENT disease (table 5).

The majority of patients had one or more comorbidities (table 5) with a high prevalence of anxiety (39.5\%), gastro-oesophageal reflux disease (GORD; 39.1\%), arterial hypertension (25.5\%) and obstructive sleep apnoea syndrome (11\%). Using the HADS, we identified anxiety and depression in $43.3 \%$ and $23.6 \%$, respectively, of severe asthma patients, which was greatly consistent with the physician's judgment. Aspirin sensitivity was present in $160(10.9 \%)$ patients, and Widal syndrome was diagnosed in 101 (6.9\%) patients (table 5).

Allergic sensitisation tests and/or blood eosinophils counts were performed for almost all patients (92.1\%; table 6). Patients were mostly allergic to dust mites (77.5\%) and pollens (57\%). The blood eosinophil count was $>300$ cells $\cdot \mathrm{mm}^{-3}$ in $53.4 \%$ of patients, with a mean value of $436.8 \pm 466.4$ cells $\cdot \mathrm{mm}^{-3}$. The total serum IgE test was performed in $62.2 \%$ patients; the mean total IgE was $546.1 \pm 1013.2 \mathrm{UI} \cdot \mathrm{L}^{-1}$.

Spirometry was conducted in $98.2 \%$ of severe asthmatic patients and was most often performed in a short period prior to the study ( $\sim 90 \%$ patients had a spirometry test in the previous 6 months). Prebronchodilator forced expiratory volume in $1 \mathrm{~s}\left(\mathrm{FEV}_{1}\right)$ and the ratio of $\mathrm{FEV}_{1}$ to forced vital capacity were $72.1 \%$ predicted and $70.2 \%$ pred, respectively. The intake of $\beta_{2}$-agonists led to a minimum $10 \%$ increase of $\mathrm{FEV}_{1}$ in $33.4 \%$ of patients, reflecting the persistence of a significant reversibility of bronchial obstruction (table 7).

Exhaled nitric oxide was measured in only 64 (4.4\%) patients, whereas chest and ENT computed tomography scans were performed in $52 \%$ and $16 \%$ of patients, respectively (table 7 ).

\section{Therapeutic management}

Almost all patients $(\mathrm{n}=1443)$ with severe asthma received a long-term treatment in addition to SABA. $\sim 90 \%$ of the patients received a combination of ICS and LABA. ICS/LABA therapy was mainly used at high doses, with $44.5 \%$ of patients receiving a dose $>1001 \mu \mathrm{g} \cdot \mathrm{day}^{-1}$ (equivalent dose of beclomethasone dipropionate). In addition, use of antileukotriene drugs (52.2\%), anticholinergic drugs (34\%), anti-IgE (26.8\%), continuous oral corticosteroids (16.8\%) and theophylline (6.7\%) was frequently observed. Among concomitant therapies, $45 \%$ patients received antihistamine treatment and $33.2 \%$ received a treatment for GORD (table 8). 


\begin{tabular}{|c|c|}
\hline \multicolumn{2}{|l|}{ TABLE 2 Patient characteristics } \\
\hline Subjects $\mathrm{n}$ & 1465 \\
\hline Female & 921 (63) \\
\hline Age years & $54.4 \pm 16.1$ \\
\hline $18-39$ & 281 (19) \\
\hline $40-59$ & $586(40)$ \\
\hline$\geqslant 60$ & $598(41)$ \\
\hline BMI $\mathrm{kg} \cdot \mathrm{m}^{-2}$ & $27.6 \pm 6.2$ \\
\hline$<18$ & $45(3)$ \\
\hline $18-24.99$ & 512 (35) \\
\hline $25-29.99$ & $473(32)$ \\
\hline$\geqslant 30$ & $435(30)$ \\
\hline \multicolumn{2}{|l|}{ Physical activity level } \\
\hline No activity & 440 (32) \\
\hline Occasional & $528(38)$ \\
\hline Regular & $323(23)$ \\
\hline Common or at competition level & 99 (7) \\
\hline Missing data & 75 \\
\hline \multicolumn{2}{|l|}{ Educational level } \\
\hline Ongoing & $8(1)$ \\
\hline No diploma & 420 (32) \\
\hline Certificate of general education (junior high school) & $413(31)$ \\
\hline Baccalaureate (high school) & $200(15)$ \\
\hline Post-baccalaureate diplomas (bachelor and graduate) & $285(21)$ \\
\hline Missing data & 139 \\
\hline \multicolumn{2}{|l|}{ Professional status } \\
\hline Active & $596(42)$ \\
\hline Inactive & $311(22)$ \\
\hline Retired & $511(36)$ \\
\hline Missing data & 47 \\
\hline \multicolumn{2}{|l|}{ Smoking status } \\
\hline Current smokers & $170(12)$ \\
\hline Ex-smokers & $424(29)$ \\
\hline Non-smokers & $871(60)$ \\
\hline Smoking history pack-years ${ }^{-1}$ & $17.9 \pm 14.8$ \\
\hline \multicolumn{2}{|l|}{ History of atopy } \\
\hline Personal atopy & $958(65)$ \\
\hline Familial atopy & 566 (39) \\
\hline \multicolumn{2}{|l|}{ Animal exposure } \\
\hline Domestic animals & $610(42)$ \\
\hline Dogs & 385 (63) \\
\hline Cats & $341(56)$ \\
\hline Others (rabbits, rodents, birds, ...) & $64(11)$ \\
\hline Nondomestic animals & $115(8)$ \\
\hline \multicolumn{2}{|l|}{ Housing } \\
\hline Urban & $697(48)$ \\
\hline Rural & $391(27)$ \\
\hline Semi-rural & $377(26)$ \\
\hline Residence proximity to a pollution source & $148(10)$ \\
\hline Residence proximity to a trunk road & $290(20)$ \\
\hline
\end{tabular}

Patients had a mean adherence score of 3.4 on the MMAS-4. Based on MMAS, 835 (65\%) patients were adherent to their treatment. Based on physician opinion, $78.5 \%$ of patients were considered as highly adherent, and $>20 \%$ were considered nonadherent to their treatment (with medium or low adherence; table 8). $94.6 \%$ of patients was considered to have good inhalation technique according to their pulmonologist.

\section{Discussion}

This very large study presents a new picture for the descriptive epidemiology of severe asthma in France. We summarised cross-sectional data of $>1500$ patients with severe asthma, managed in nonacademic 


\begin{tabular}{|c|c|c|c|c|c|c|}
\hline & \multicolumn{4}{|c|}{ Control according to GINA criteria } & \multirow[t]{2}{*}{ Total } & \multirow[t]{2}{*}{ p-value } \\
\hline & $\begin{array}{l}\text { Well } \\
\text { controlled }\end{array}$ & $\begin{array}{l}\text { Partially } \\
\text { controlled }\end{array}$ & Uncontrolled & $\begin{array}{l}\text { Missing } \\
\text { data }\end{array}$ & & \\
\hline \multicolumn{7}{|l|}{$\begin{array}{l}\text { Control assessed by } \\
\text { the physician }\end{array}$} \\
\hline Well controlled & $50(10.1)$ & $229(46.1)$ & $217(43.8)$ & 11 & $507(37.4)$ & $<0.0001$ \\
\hline Partially controlled & 2 (0.3) & 98 (17) & $479(82.7)$ & 19 & $598(44.1)$ & \\
\hline Uncontrolled & $1(0.4)$ & $7(2,9)$ & $236(96.7)$ & 6 & 250 (18.5) & \\
\hline Missing data & 0 & 0 & 5 & 7 & 12 & \\
\hline Total & $53(4)$ & $334(25.2)$ & $937(70.8)$ & 43 & $1367(100)$ & \\
\hline
\end{tabular}

\section{TABLE 4 Asthma history}

$\begin{array}{lc}\text { Subjects } & 1465 \\ \text { Age at asthma onset years } & 26.9 \pm 20.4 \\ \leq 12 & 496(34) \\ 13-39 & 544(37) \\ \geqslant 40 & 417(29) \\ \text { Missing data } & 8 \\ \text { Asthma duration years } & 27.4 \pm 17.9 \\ \text { Pulmonology follow-up duration years } & 13.5 \pm 12.7 \\ \text { History of acute severe asthma } & 757(52) \\ >2 \text { exacerbations in the past year } & 949(65) \\ \text { Exacerbation history in the past year } & 2.6 \pm 3.1 \\ \quad \text { Medical consultations } & 0.5 \pm 1.3 \\ \text { Hospitalisations for asthma } & 0.6 \pm 1.7 \\ \text { Visits to emergency room } & 2.5 \pm 3.1 \\ \text { Severe exacerbation } & 35.3 \pm 68.1 \\ \text { Absenteeism from work/school due to asthma in the past year days } & \end{array}$

hospitals in 2016-2017 in France. We analysed patients' characteristics, medical history and comorbidities, as well as the clinical presentation of asthma with a detailed description of patient management (medication, adherence to treatment and asthma control).

Our data are consistent with the results of previous studies confirming the female preponderance and high occurrence of atopy in severe asthmatics [18]. Chronic rhinitis was the most common asthma-related condition, while GORD, high blood pressure and anxiety and depression were frequent in this population. These comorbidities are frequent in severe asthmatic patients, as demonstrated in previous epidemiological studies. Indeed, a recent meta-analysis based on 26 studies (cohort studies, experimental studies and severe asthma registries) conducted in severe asthma populations demonstrated that among extrapulmonary comorbidities, sinusitis, GORD, obesity and hypertension are the most frequent [18].

Furthermore, we found that tobacco use among adults with severe asthma is not rare (12\% of active smokers), illustrating the requirement for future efforts to reduce this well-known risk factor. Moreover, we confirmed the involvement of obesity and overweight in asthma, as $\sim 30 \%$ and $32 \%$ of the patients in our study were obese and overweight; respectively, indicating that these factors must be taken into consideration when addressing severe asthma.

Our analysis showed that blood eosinophils were not measured for $25 \%$ of the patients, while the serum IgE test was conducted in only $62 \%$ of patients. This may have contributed to undertreatment of patients when considering emerging therapies, such as anti-IL-5 and anti-IgE treatments [19]. Moreover, the mean blood eosinophil count was quite high at $437 \mathrm{cells} \cdot \mathrm{mm}^{-3}$, with half of patients having a count $>300$ cells $\cdot \mathrm{mm}^{-3}$, indicating the possibility of treating a large number of our population of French adults with 


\begin{tabular}{|c|c|}
\hline Subjects & 1465 \\
\hline \multicolumn{2}{|l|}{ Medical history } \\
\hline Aspirin intolerance & $160(10.9)$ \\
\hline Widal syndrome & $101(6.9)$ \\
\hline Food allergy & $153(10.5)$ \\
\hline Drug allergy & $207(14.1)$ \\
\hline Atopic dermatitis & $225(15.4)$ \\
\hline Allergic bronchopulmonary aspergillosis & $40(2.7)$ \\
\hline Churg-Strauss syndrome & $15(1)$ \\
\hline ENT disease & $862(58.9)$ \\
\hline Chronic rhinitis & $655(44.7)$ \\
\hline Chronic rhinosinusitis & 358 (24.5) \\
\hline Polyposis & $265(18.1)$ \\
\hline \multicolumn{2}{|l|}{ Comorbidities (ENT disease excluded) } \\
\hline No comorbidity & $387(26.5)$ \\
\hline 1 comorbidity & $435(29.8)$ \\
\hline 2 comorbidities & $290(19.8)$ \\
\hline$\geqslant 3$ comorbidities & $350(23.9)$ \\
\hline Missing data & 3 \\
\hline Gastro-oesophageal reflux disease & $573(39.1)$ \\
\hline Arterial hypertension & $372(25.5)$ \\
\hline Diabetes & $149(10.2)$ \\
\hline Ischaemic cardiopathy & $72(5)$ \\
\hline Sleep apnoea & $161(11)$ \\
\hline Osteoporosis & $156(10.7)$ \\
\hline Anxiety & 579 (39.5) \\
\hline Depression & $208(14.2)$ \\
\hline Other mental disorder & $32(2.2)$ \\
\hline Anxiety and depression determined with self-assessment questionnaires & 1367 \\
\hline Anxiety level (HADS-A) & $7.4 \pm 4.4$ \\
\hline Presence of anxiety (score >7) & $583(43.3)$ \\
\hline Absence of anxiety (score $\leqslant 7$ ) & $763(56.7)$ \\
\hline Missing data & 21 \\
\hline Depression level (HADS-D) & $5.1 \pm 3.8$ \\
\hline Presence of depression (score >7) & $320(23.6)$ \\
\hline Absence of depression (score $\leqslant 7$ ) & $1038(76.4)$ \\
\hline Missing data & 9 \\
\hline
\end{tabular}

Data are presented as $n, n(\%)$ or mean \pm SD. ENT: ear, nose and throat; HADS: Hospital Anxiety and Depression Scale; A: anxiety; D: depression.

severe asthma with anti-IL-5. Finally, the very high percentage of patients with skin tests, blood eosinophils and spirometry suggest a good quality of the approach to severe asthma with relevant objective measurements.

Lung function testing was conducted in almost all patients in our study population, with the last assessment conducted during the previous 6 months. This reflects the current recommendations for the management of severe asthma, as the periodical measurement of lung function is an integral part of control assessment [6]. Furthermore, and despite its well-known clinical utility, only half of the patients benefited from computed tomography. Since this examination is important in the diagnosis of asthma complications and associated conditions [20], its broader use could help improve management and increase control of the disease. As expected considering the guidelines for severe asthma management [6], we found that exhaled nitric oxide is poorly assessed in current practice, in $<5 \%$ of patients.

In addition to SABA, a high proportion of severe asthmatics in France (90\%) received a combination of ICS and LABA, with a mean dose of $1326 \mu \mathrm{g} \cdot$ day $^{-1}$ (beclomethasone dipropionate equivalent). These results are coherent with current GINA recommendations and previous studies conducted across the world [21-23]. Antileukotriene treatment was used in $52.2 \%$ of the French severe asthmatics, which is a slightly lower percentage than the $65 \%$ in the Belgian registry including 350 patients [23], but similar to that in the Italian registry including 493 patients [24]. The results of these two studies were overall similar to ours, but were conducted on smaller samples. For example, we found that the same proportion of French 


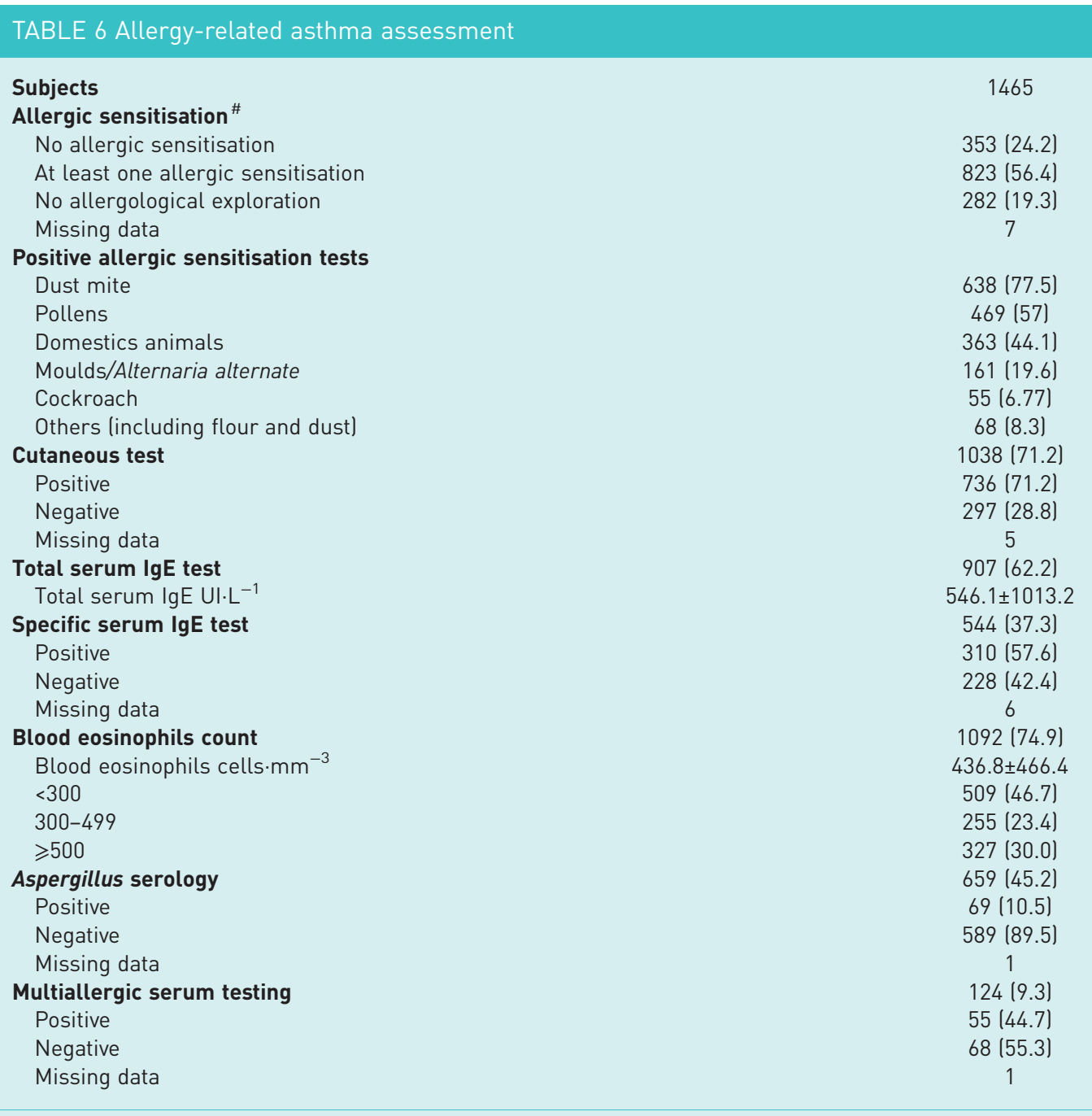

Data are presented as $\mathrm{n}, \mathrm{n}(\%)$ or mean $\pm \mathrm{SD}$. Ig: immunoglobulin. ${ }^{\#}$ : defined by positive cutaneous test or positive specific serum IgE test.

patients were treated with anticholinergic (34\%) and anti-IgE therapies (27\%) as in the Belgian registry. Maintenance oral corticosteroids (17\%) and theophylline (7\%) were found in similar frequencies as in the Italian registry (24\%), but were lower than in the other registries [21-23, 25]. The values of baseline $\mathrm{FEV}_{1}$ were slightly different between the FASE-CPHG population ( $72 \%$ pred), the Belgian registry ( $68 \%$ pred) and the Italian registry (75\%); however, these differences cannot explain differences in the add-on treatment prescription in the three studies, such as the high rate $(64 \%)$ of Italian patients receiving anti-IgE treatment.

Only $4 \%$ of the French severe asthmatics were well controlled according to the GINA guidelines, while $65 \%$ were adherent to treatment. Uncontrolled asthma was also observed in the COBRA study including a French population of severe asthmatics in which $>60 \%$ of patients were uncontrolled [26]. Overall, our study shows that physicians tend to overestimate asthma control. Since poor control is a burden for patients and a risk factor for exacerbations, a good evaluation is required in order to better manage patients. Our results show that asthma control assessment during patient visits needs to be improved in France, and strategies for patients are required to improve compliance for better controlling asthma. We expect that exhaustive investigation of the disease will be performed in the future according to new treatments, which were not available at the time of this study.

Despite these interesting results, our study has some limitations. First, its cross-sectional design did not allow us to establish causal associations and descriptions of follow-up. However, our main objective was to produce a comprehensive update on the characteristics of severe asthmatic patients and on practice 


\begin{tabular}{|c|c|}
\hline Subjects & 1465 \\
\hline$\alpha_{1}$-antitrypsin test & $157(10.8)$ \\
\hline$<0.8 \mathrm{~g} \cdot \mathrm{L}^{-1}$ & 6 (3.8) \\
\hline $0.8-0.99 \mathrm{~g} \cdot \mathrm{L}^{-1}$ & $4(2.6)$ \\
\hline$\geqslant 1 \mathrm{~g} \cdot \mathrm{L}^{-1}$ & 145 (93.5) \\
\hline Mean result $\mathrm{g} \cdot \mathrm{L}^{-1}$ & $1.3 \pm 0.4$ \\
\hline Pulmonary function tests & $1321(98.2)$ \\
\hline Time since last spirometry months & $2.1 \pm 8$ \\
\hline Last spirometry assessed during the visit & $862(65.6)$ \\
\hline$\leqslant 6$ months & $329(25)$ \\
\hline $6-12$ months & $64(4.9)$ \\
\hline$>12$ months & $59(4.5)$ \\
\hline Missing data & 7 \\
\hline Pre-bronchodilator FEV1 \% pred & $72.1 \pm 20.6$ \\
\hline Post-bronchodilator FEV1 \% pred & $77.1 \pm 20.5$ \\
\hline Pre-bronchodilator FEV $1 / F V C \%$ pred & $70.2 \pm 14.4$ \\
\hline $\mathrm{FEV}_{1} / \mathrm{FVC}<70 \%$ pred & $20 \%$ \\
\hline \multicolumn{2}{|l|}{ FEV 1 evolution after $\boldsymbol{\beta}_{2}$-agonists $\%$} \\
\hline No evolution & 243 (18.5) \\
\hline Increase $<10 \%$ & $363(27.1)$ \\
\hline Increase $\geqslant 10 \%$ & $304(33.4)$ \\
\hline Missing data & 411 \\
\hline Exhaled nitric oxide measurements & $64(4.4)$ \\
\hline Results ppb & $37.5 \pm 26.2$ \\
\hline Chest CT scan & 754 (51.8) \\
\hline Bronchiectasis & $156(22)$ \\
\hline Bronchial wall thickening & $307(44)$ \\
\hline Emphysema & $108(15,5)$ \\
\hline ENT CT scan & $466(16)$ \\
\hline Absence of clinical signs & 135 (30.7) \\
\hline Polyps & $119(27)$ \\
\hline Chronic sinusitis & 186 (42.3) \\
\hline Missing data & 26 \\
\hline
\end{tabular}

Data are presented as $n, n(\%)$ or mean \pm SD. $F E V_{1}$ : forced expiratory volume in $1 \mathrm{~s}$; FVC: forced vital capacity; CT: computed tomography; ENT: ear, nose and throat.

regarding the latest scientific progress. A constitution of cohorts with longitudinal follow-up could help to better define the relationship between asthma severity, control and adherence, as well as in the development of efficient practice in the management of asthma in France. Second, the design of the questionnaires did not allow us to perform an exhaustive assessment of comorbidities. Indeed, we chose to focus on pathologies more known to be associated with asthma. Moreover, since these data are declarative and some of these pathologies are underdiagnosed, comorbidity results could be underestimated and should be interpreted with caution. Despite these limitations, this study offers a good geographic representation of the disease. Participating centres were equitably distributed throughout the national territory, and all French regions were represented. Moreover, the participating physicians were asked to include their patients in an exhaustive manner. Thus, our data can be considered to be representative of the current real-world management of severe asthmatic patients in France.

In summary, this FASE-CPHG study is the largest French study and one of the largest worldwide studies to describe severe asthma in adults, with 1502 patients included. Severe asthmatics included in this study have similar characteristics to those previously described across European and American populations. To our knowledge, this is the first study providing an important overview of recent practice in the management of severe asthmatics in nonacademic hospitals in France in such a large sample. Our data indicate that general hospitals in France provide high quality management to severe asthmatics which is in accordance with the current recommendations of the European Respiratory Society and American Thoracic Society, and the GINA guidelines [2, 14]. However, control assessment, optimisation of treatment, as well as adherence to treatment, could be improved, for example by using standardised monitoring procedures or by creating a French registry. These data on epidemiology, management and therapy choices for severe asthma will help pulmonologists in more efficient patient characterisation and 


\begin{tabular}{|c|c|}
\hline \multicolumn{2}{|l|}{ TABLE 8 Medications } \\
\hline Subjects & 1465 \\
\hline No LABA/ICS & $22(1.5)$ \\
\hline Inhaled corticosteroids only ${ }^{\#}$ & $136(9.3)$ \\
\hline$<500 \mu \mathrm{g} \cdot \mathrm{day}^{-1}$ & $21(15.4)$ \\
\hline $500-1000 \mu \mathrm{g} \cdot \mathrm{day}^{-1}$ & $41(30.1)$ \\
\hline $1000-2000 \mu \mathrm{g} \cdot \mathrm{day}^{-1}$ & 57 (41.9) \\
\hline$>2000 \mu \mathrm{g} \cdot \mathrm{day}^{-1}$ & $15(11)$ \\
\hline LABAs only & $106(7.2)$ \\
\hline ICS/LABA combination ${ }^{\#}$ & $1326(90.5)$ \\
\hline$<500 \mu \mathrm{g} \cdot \mathrm{day}^{-1}$ & $62(4.7)$ \\
\hline $500-1000 \mu \mathrm{g} \cdot \mathrm{day}^{-1}$ & $419(31.6)$ \\
\hline $1000-2000 \mu \mathrm{g} \cdot \mathrm{day}^{-1}$ & $590(44.5)$ \\
\hline$>2000 \mu \mathrm{g} \cdot \mathrm{day}^{-1}$ & $253(19.1)$ \\
\hline Anticholinergic treatment & $498(34)$ \\
\hline Antileukotriene (montelukast) & 759 (52.2) \\
\hline Long-term oral corticosteroid therapy & 245 (16.8) \\
\hline Mean daily dose $\mathrm{mg}^{\pi}$ & $19.4 \pm 34.2$ \\
\hline Anti-IgE (omalizumab) & $390(26.8)$ \\
\hline Dose mg & $347 \pm 155.3$ \\
\hline \multicolumn{2}{|l|}{ Frequency of treatment } \\
\hline Every 2 weeks & $180(46.9)$ \\
\hline Every 4 weeks & $204(53.1)$ \\
\hline Missing data & 6 \\
\hline Duration of treatment years & $3.1 \pm 2.6$ \\
\hline Theophylline & $97(6.7)$ \\
\hline \multicolumn{2}{|l|}{ Other therapies } \\
\hline Long-term azithromycin & $84(5.6)$ \\
\hline Antihistamine & $655(45)$ \\
\hline Antidepressants & $121(8.3)$ \\
\hline$\beta$-blocker & $26(1.8)$ \\
\hline Anti-GORD & 483 (33.2) \\
\hline Postmenopausal hormone therapy & $14(1.5)$ \\
\hline Desensitisation in the previous 5 years & $54(3.7)$ \\
\hline Alternative medicine & $84(5.8)$ \\
\hline \multicolumn{2}{|c|}{ Patient adherence level according to physician } \\
\hline High & $1063(78.5)$ \\
\hline Medium & $245(18.1)$ \\
\hline Low & $47(3.5)$ \\
\hline Adherence level MMAS-4 score & $3.4 \pm 1$ \\
\hline Adherent patient (score=4) & $835(64.8)$ \\
\hline Non-adherent patients (score $<4$ ) & $454(35.2)$ \\
\hline Missing data & 78 \\
\hline
\end{tabular}

in making appropriate treatment decisions. This study could also be interesting for companies to better understand this form of asthma, in order to develop new treatments. Furthermore, improving knowledge on this pathology and its current management could lead to a reduction of the tremendous costs related to the disproportionate use of medical resources to manage frequent exacerbations, which are part of severe asthma when uncontrolled. Further studies are still needed to better characterise and understand severe asthma, to identify potential associated features and biomarkers, which can provide new specific treatments for this pathology. Additional analyses of FASE-CPHG data are underway to better understand this disease, particularly in terms of phenotype description and management.

Acknowledgements: The authors would like to thank Vanessa Cohignac, Hélène Le Cloarec, Mathilde Pouriel and Nathalie Texier from Kappa Santé (Paris, France), a contract research organisation, for the operational management of the study, data analysis and preparation of the study report and the present article. The authors would also like to share compassionate thoughts for Juliette Ostinelli. 
MMAS-8 and MMAS-4 are protected by US and International Trademark and Copyright laws. Permission for use is required. A license agreement is available from: MMAS Research LLC 14725 NE $20^{\text {th }}$ Bellevue WA 98007.

The authors thank the FASE-CPHG participants and investigators for making this study possible: Dr Parrat $(\mathrm{CH}$ Papeete); Dr Nocent (CH Bayonne); Dr Mangiapan (CHI Créteil); Dr Prud'homme and Dr Courdeau-Labourie and Dr Demaegdt (CH Tarbes); Dr Oster and Dr Moreau and Dr Allibe (CH Colmar); Dr Portel and Dr Roy (CH Libourne); Dr Appere De Vecchi ( $\mathrm{CH}$ Argenteuil); Dr Maurer ( $\mathrm{CH}$ Montfermeil); Dr Lepoulain Doubliez (CH Charleville Mezières); Dr Iamandi (CH Mulhouse); Dr Gourcerol (CH Pau); Dr Didi, Dr Decroisette and Dr Bertocchi (CH Pringy); Dr Barbare and Dr Moncelly (CH Meaux); Dr Tannous (CH Forbach); Dr Kelkel (CH Chambéry); Dr Rolland (CH Cannes); Dr Jouveshomme (Hôpital St-Joseph, Paris); Dr Bernier (CH Dinan); Dr Hauss, Dr Ould, Dr Vincent, Dr Van Mossevelde and Dr Gallego (CH Elbeuf); Dr Merzoug (CH Fougères); Dr Haddad (CH Lourdes); Dr Guerrero, Dr Jarjour, Dr Haouachi and Dr Goutorbe (CH Béziers); Dr Morel, Dr Lemaire and Dr Russier (CH Orléans); Dr Roge (CH Morlaix); Dr Dumont (CH Chauny); Dr Cavestri and Dr Just (CH Roubaix); Dr Colin (CH Versailles); Dr Goupil, Dr Mansour and Dr Paris (CH Le Mans); Dr Philippe and Dr Boitiaux ( $\mathrm{CH}$ Cergy-Pontoise); Dr Simon (CH Compiègne); Dr Marcq, Dr Bizieux, Dr Guibert and Dr Caby (CH La Roche sur Yon); Dr Lecuyer (CH Saint-Quentin); Dr Merlusca (CH Sedan); Dr Blanc (CH Aix en Provence); Dr Langelot (CH Les Sables d'Olonne); Dr Tagu (CH Bar le Duc); Dr Leveiller, Dr Duriel-Niel and Dr Coëtmeur (CH Saint-Brieuc); Dr Ilie (CH Dunkerque); Dr Raspopa $(\mathrm{CH}$ Toulon); Dr Lerousseau and Dr Rotomondo (CH Antibes); Dr Gramada (CH Sarreguemines); Dr Cornu and Dr Petit (CH Verdun); Dr Kraemer (CH Fréjus); Dr Guy (CH Vannes); Dr Gentil, Dr Luciani and Dr Lucena (CH Bourgoin Jallieu); Dr Michaux (CH Macon); Dr Maitre (CH Vesoul); Dr De Faverges (CH Nevers); Dr Fouret (CH Villeneuve Saint-Georges); Dr Goarant (CH Saint-Malo); Dr Bara and Dr Hamoudi (CH Angoulême); Dr Maetz (CH Douai); Dr Yousef and Dr Lungoci (CH Le Puy en Velay); Dr Al Freijat (CH Belfort); Dr Assemi (CH Saverne); Dr Beysens (CH Saintes); Dr Clarissou (CH Beaumont sur Oise); Dr Karimo (CH Saint-Omer); Dr Saadi (CH Barbezieux Saint Hilaire); Dr Barre and Dr Farny (CH Cahors); Dr Romand (CH Contamine sur Arve); Dr Leleu (CH Abbeville); Dr Bernard (CH Quimper); Dr Marangoni (CH Saint-Dié); Dr Fevrier ( $\mathrm{CH}$ Saumur); Dr Paillot $(\mathrm{CH}$ Metz); Dr Bonnefoy $(\mathrm{CH}$ Jonzac); Dr Manoila (CH Evreux); Dr Abraham (CH Dax); Dr Lacroix (CH Périgueux); Dr Virally (CH Aulnay sous Bois).

Support statement: The FASE-CPHG study was supported by contributions made through the CPHG from ALK, AstraZeneca, Boehringer Ingelheim, GSK, and Le Nouveau Souffle. Funding information for this article has been deposited with the Crossref Funder Registry.

Conflict of interest: None declared.

\section{References}

1 Bousquet J, Mantzouranis E, Cruz AA, et al. Uniform definition of asthma severity, control, and exacerbations: document presented for the World Health Organization Consultation on Severe Asthma. J Allergy Clin Immunol 2010; 126: 926-938

2 Chung KF, Wenzel SE, Brozek JL, et al. International ERS/ATS guidelines on definition, evaluation and treatment of severe asthma. Eur Respir J 2014; 43: 343-373.

3 Raherison C, Janson C, Jarvis D, et al. Evolution of asthma severity in a cohort of young adults: is there any gender difference? PLoS One 2009; 4: e7146.

4 Raherison-Semjen C, Izadifar A, Russier M, et al. Asthma prevalence and management in adults in France in 2018: ASTHMAPOP survey. Eur Respir J 2018; 52: OA292.

5 Raherison C, Bourdin A, Bonniaud P, et al. Updated guidelines (2015) for management and monitoring of adult and adolescent asthmatic patients (from 12 years and older) of the Société de Pneumologie de Langue Française (SPLF) (Full length text). Rev Mal Respir 2016; 33: 279-325.

6 Chung KF. Managing severe asthma in adults: lessons from the ERS/ATS guidelines. Curr Opin Pulm Med 2015; 21: $8-15$.

7 Accordini $\mathrm{S}$, Corsico AG, Braggion $\mathrm{M}$, et al. The cost of persistent asthma in Europe: an international population-based study in adults. Int Arch Allergy Immunol 2013; 160: 93-101.

8 Wenzel SE. Asthma phenotypes: the evolution from clinical to molecular approaches. Nat Med 2012; 18: 716-725.

9 King GG, James A, Harkness L, et al. Pathophysiology of severe asthma: we've only just started. Respirology 2018; 23: 262-271.

10 Papathanassiou E, Loukides S, Bakakos P. Severe asthma: anti-IgE or anti-IL-5? Eur Clin Respir J 2016; 3: 31813.

11 Bel EH, Ten Brinke A. New anti-eosinophil drugs for asthma and COPD: targeting the trait! Chest 2017; 152: $1276-1282$.

12 Debieuvre D, Locher $\mathrm{C}$, Neidhardt $\mathrm{A}-\mathrm{C}$, et al. Évolution en 10 ans du cancer bronchique non à petites cellules en fonction du sexe. Résultats de l'étude KBP-2010-CPHG du Collège des pneumologues des hôpitaux généraux. [Ten-year evolution in non-small-cell lung cancer according to sex. Results of the KBP-2010-CPHG study by the College of General Hospital Respiratory Physicians]. Rev Mal Respir 2014; 31: 805-816.

13 Blanchon F, Grivaux M, Collon T, et al. [Epidemiologic of primary bronchial carcinoma management in the general French hospital centers]. Rev Mal Respir 2002; 19: 727-734.

14 Global Initiative for Asthma (GINA). Global Strategy for Asthma Management and Prevention. 2018. Available from: http://ginasthma.org

15 Morisky DE, Ang A, Krousel-Wood M, et al. Predictive validity of a medication adherence measure in an outpatient setting. J Clin Hypertens 2008; 10: 348-354.

16 Morisky DE, DiMatteo MR. Improving the measurement of self-reported medication nonadherence: response to authors. J Clin Epidemiol 2011; 64: 255-257.

17 Krousel-Wood M, Islam T, Webber LS, et al. New medication adherence scale versus pharmacy fill rates in seniors with hypertension. Am J Manag Care 2009; 15: 59-66.

18 Clark VL, Gibson PG, Genn G, et al. Multidimensional assessment of severe asthma: a systematic review and meta-analysis. Respirology 2017; 22: 1262-1275. 
19 Diver S, Russell RJ, Brightling CE. New and emerging drug treatments for severe asthma. Clin Exp Allergy 2018; 48: 241-252.

20 Ash SY, Diaz AA. The role of imaging in the assessment of severe asthma. Curr Opin Pulm Med 2017; 23: 97-102.

21 Braunstahl G-J, Leo J, Thirlwell J, et al. Uncontrolled persistent allergic asthma in practice: eXpeRience registry baseline characteristics. Curr Med Res Opin 2011; 27: 761-767.

22 Gibson PG, Reddel H, McDonald VM, et al. Effectiveness and response predictors of omalizumab in a severe allergic asthma population with a high prevalence of comorbidities: the Australian Xolair Registry. Intern Med J 2016; 46: 1054-1062.

23 Schleich F, Brusselle G, Louis R, et al. Heterogeneity of phenotypes in severe asthmatics. The Belgian Severe Asthma Registry (BSAR). Respir Med 2014; 108: 1723-1732.

24 Maio S, Baldacci S, Bresciani M, et al. RItA: The Italian severe/uncontrolled asthma registry. Allergy 2018; 73 683-695.

25 Moore WC, Bleecker ER, Curran-Everett D, et al. Characterization of the severe asthma phenotype by the National Heart, Lung, and Blood Institute's Severe Asthma Research Program. J Allergy Clin Immunol 2007; 119: 405-413.

26 Pretolani M, Soussan D, Poirier I, et al. Clinical and biological characteristics of the French COBRA cohort of adult subjects with asthma. Eur Respir J 2017; 50: 1700019. 